\title{
O lado sombrio da migração irregular no Reino Unido, no filme Coisas belas e sujas
}

The Dark Side of Irregular Migration to the United Kingdom in the Film Dirty Pretty Things

Le côté sombre de la migration irrégulière au Royaume-Uni dans le film Loin de chez eux

\section{Paulo Rogério Melo de Oliveira}

\section{OpenEdition}

\section{Journals}

Edição electrónica

URL: https://journals.openedition.org/rccs/11558

DOI: $10.4000 /$ rccs. 11558

ISSN: 2182-7435

\section{Editora}

Centro de Estudos Sociais da Universidade de Coimbra

\section{Edição impressa}

Data de publição: 1 maio 2021

Paginação: 79-98

ISSN: 0254-1106

\section{Refêrencia eletrónica}

Paulo Rogério Melo de Oliveira, «O lado sombrio da migração irregular no Reino Unido, no filme Coisas belas e sujas», Revista Crítica de Ciências Sociais [Online], 124 | 2021, publicado a 26 maio 2021

consultado a 28 maio 2021. URL: http://journals.openedition.org/rccs/11558 ; DOI: https://doi.org/ $10.4000 /$ rccs. 11558 


\section{PAULO ROGÉRIO MELO DE OLIVEIRA}

\section{O lado sombrio da migração irregular no Reino Unido, no filme Coisas belas e sujas}

O artigo propõe uma interpretação do filme de 2002 Coisas belas e sujas (Dirty Pretty Things, no original) - do cineasta britânico Stephen Frears - entendendo-o como uma tomada de posição política sobre os movimentos migratórios globais e, particularmente, em relação à política migratória britânica do início do século XXI. No filme, migrantes em situação irregular, que sobrevivem em Londres à base de empregos precários e provisórios e jornadas extenuantes, envolvem-se involuntariamente com o tráfico internacional de órgãos humanos e passaportes falsificados. A metodologia de análise fílmica combina a abordagem contextualista de Marc Ferro, que nos convida a explorar os diálogos do filme com o mundo social, com a proposta semiótica de Pierre Sorlin, com o auxílio da qual interpretamos os signos e metáforas que constroem os sentidos internos da narrativa fílmica.

Palavras-chave: cinema; migrações; migrante clandestino; Reino Unido; representação cinematográfica.

\section{Introdução}

O thriller tenso e sombrio Coisas belas e sujas (Dirty Pretty Things, no original), de 2002, do cineasta britânico Stephan Frears, explora as experiências de migrantes irregulares em Londres envolvidos involuntariamente com o tráfico internacional de órgãos humanos. Produzido num momento em que os deslocamentos populacionais provocados pela fome, pelas guerras e pela ação de grupos extremistas alcançavam números preocupantes, ${ }^{1}$

\footnotetext{
${ }^{1}$ Segundo o "World Economic and Social Survey 2004" (UN, 2004: vii, 25), no ano 2000, cerca de 175 milhões de pessoas viviam fora do país de origem, sendo que uma em cada 35 pessoas era migrante - o que corresponderia a $2,9 \%$ da população mundial. Destes, cerca de 158 milhões foram considerados migrantes internacionais, aproximadamente 16 milhões eram refugiados e 900 mil eram requerentes de asilo (ibidem: vii). No Reino Unido, de acordo com as estatísticas do Home Office, o número total de migrantes que entraram por mais de um ano subiu de 326100 em 1997 para 582100 em 2004, enquanto a taxa de migração líquida aumentou de 46800 para 222600 (Somerville, 2007).
} 
o filme se oferece como um "documento" contundente (Ferro, 1992) $)^{2}$ para pensarmos criticamente as migrações globais. Simultaneamente, reflete um posicionamento político de Stephan Frears, o que faz do filme um "monumento" "sobre as migrações contemporâneas. Atento a estas duas formas sob as quais os materiais de memória coletiva se apresentam (Napolitano, 2007), utilizo a noção de "documento/monumento"4 para problematizar as especificidades do cinema como arte, com sua linguagem e modos de significação específicos, e como um produto social e cultural da sociedade em que foi produzido. Neste sentido, Coisas belas e sujas dialoga com as tensões da sociedade britânica em relação à presença da força de trabalho estrangeira e com os sentidos das migrações do final do século xx e início do XXI.

Existe uma produção expressiva de filmes sobre as migrações contemporâneas, com olhares incisivos e problematizadores de cineastas de vários continentes. O número de Festivais de Cinema espalhados pelo mundo - exibindo uma grande variedade de filmes e documentários, em competição ou não - é um forte indicativo de que o tema, contrariando as políticas dos Estados de controle restritivo nas fronteiras e as crescentes manifestações xenófobas, tem ampla capacidade de mobilização de público. Demonstra ainda que o cinema é um dos mais importantes meios de promoção da reflexão crítica - com o propósito de "desafiar o estreitamento das percepções" (Shapiro, 2009) - e de sensibilização sobre os efeitos perversos das políticas

\footnotetext{
${ }^{2}$ Marc Ferro (1992) entende o filme como um "documento", pois auxilia o historiador na construção de uma contra-história, ou seja, de uma história não oficial.

3 Os "monumentos", heranças do passado, carregam a intenção de deixar à posteridade um conjunto de sentidos sobre acontecimentos históricos (Ferro, 1992; Napolitano, 2007).

${ }^{4}$ A noção de documento é inspirada nas proposições de Michel Foucault e Jacques Le Goff sobre o "documento/monumento". Tomar o documento como monumento é submetê-lo a uma crítica arqueológica que nos permite uma análise interna do documento a fim de explicitar a teia de saberes que o constitui e os poderes que o sustentam (Foucault, 1987). Compartilhando da visão de Foucault, Le Goff (1984: 103) radicalizou o "dever principal" do historiador de fazer a "crítica do documento enquanto monumento". Considerado desta maneira, o documento deixa de ser visto como "qualquer coisa que fica por conta do passado" e passa a ser encarado como um "produto da sociedade que o fabricou segundo as relações de força que aí detinham o poder" (ibidem: 104). O documento é monumento pois "resulta do esforço das sociedades históricas para impor ao futuro - voluntária ou involuntariamente - determinada imagem de si próprias" (ibidem: 105). Daí a necessidade de "analisar as condições de produção dos documentos/monumentos" (ibidem). No limite, não existem documentos inocentes, inócuos ou objetivos, como pretendiam os historiadores "tradicionais". Todo o documento é monumento na medida em que supõe uma intencionalidade, encerra determinadas relações de poder e projeta para o futuro uma imagem desejada de alguém, de uma instituição, de um acontecimento, ainda que involuntariamente. O sentido comum atribuído à palavra monumento vem carregada desta intencionalidade, de uma "construção destinada a transmitir à posteridade a memória de fato ou pessoa notável" (ibidem). O binômio documento/monumento chama a atenção exatamente para este sentido de construção, ou de montagem como diz Le Goff (ibidem: 102).
} 
e dos critérios de controle seletivo dos Estados em relação aos movimentos globais de população.

As migrações globais ocupam o centro dos debates sobre a globalização e as tendências políticas de diversos países (Grimson, 2011). Quase diariamente as agências de notícias, os sites especializados e os canais de televisão informam sobre levas de migrantes que deixam seus locais de origem, pelos mais diferentes motivos, em situações dramáticas, e tentam entrar clandestinamente em outros países. ${ }^{6}$ O Mediterrâneo, porta de entrada para a Europa, transformou-se num triste cenário e espelho trágico das migrações neste começo de século. Os naufrágios frequentes, os milhares de mortos, as balsas improvisadas lotadas, o grande número de crianças e os resgates dramáticos dos sobreviventes nos dão bem a dimensão da tragédia - e do espetáculo midiático seletivo no qual se converteram as migrações. A multiplicação dos campos de refugiados em vários continentes, que acolhem milhares de pessoas deslocadas pelas guerras e pelos conflitos (principalmente na África e no Oriente Médio), expõe, de um lado, a extrema vulnerabilidade humana e, de outro, na visão de alguns observadores, a associação ambígua entre a guerra e as ações humanitárias, expressa na fórmula provocativa "uma mão que fere, a outra que socorre" (Agier, 2006). Esta nova faceta dos deslocamentos mundiais se distingue ainda das migrações do pós-Segunda Guerra Mundial pelo caráter mais fluído e temporário dos deslocamentos. Se os migrantes daquele período buscavam laços mais permanentes com os países que os recebiam e lutavam para serem reconhecidos enquanto cidadãos nacionais, os migrantes contemporâneos não estão empenhados, como antes, em reivindicar a pertença, mantêm-se em movimento e, em muitos casos, escondem suas verdadeiras identidades (Graham, 2011). Esta configuração global dos fluxos migratórios, envolvendo todos os continentes e tipos de migrantes já não pode mais ser explicada pelas relações históricas (Inglaterra/Índia, Paquistão e região de Bengala)

\footnotetext{
${ }^{5} \mathrm{Na}$ última década, os Festivais de Cinema abordando as migrações internacionais surgiram em vários países como Angola, Argentina, Suécia, Portugal continental e Açores, Brasil e França. Diante da onda conservadora condenatória das migrações, que cresce na Europa e nos Estados Unidos, os Festivais se afiguram como verdadeiras "heterotopias cinematográficas" (Shapiro, 2009), a desafiar a violência e as práticas de subjugação e discriminação que cercam os deslocamentos populacionais nas últimas décadas.

${ }^{6}$ Em 2015, o número de migrantes alcançou a marca de 244 milhões de pessoas, o que representa um aumento de $41 \%$ em relação a 2000 (ONUBR News, 2016). Este aumento foi mais rápido do que o crescimento da população mundial (ibidem). Os deslocamentos forçados também tiveram um incremento expressivo, tendo afetado, em 2015, 63,5 milhões de pessoas - um aumento de 10\% se comparado com 2014 (ibidem). A mortalidade decorrente das condições precárias dos meios de deslocamentos cresce assustadoramente (ibidem). Assim, de acordo com a Organização Internacional das Migrações, até meados de 2016 mais de 3 mil pessoas fugindo das guerras e da fome em África morreram afogadas no Mediterrâneo, entre a costa da Líbia e a Itália (Ordaz, 2016).
} 
ou geográficas (Estados Unidos da América/México) entre os países de partida e os de acolhida. A multiplicidade e a complexidade dos deslocamentos, que alcança hoje todos os países desenvolvidos, escapam aos projetos dos Estados-nação e, cada vez mais, se inscrevem na ordem e na desordem da globalização (Hily, 2003: 8). Tomemos um exemplo que pode nos auxiliar mais à frente. Os migrantes indianos, bengalis e paquistaneses, que na década de 1970 e começo dos anos 1980 procuravam o Reino Unido para viver, faziam-no pelos laços históricos e culturais dos seus países com o colonialismo britânico. Os outros migrantes, de diferentes nacionalidades africanas e asiáticas (entre outras), cujos países não estabeleceram estes laços profundos com o Império Britânico, deslocam-se para o Reino Unido por outros motivos, entre os quais a busca por empregos e o acesso a benefícios sociais do Estado.

A política britânica de imigração oscila historicamente, por conta das conjunturas econômicas e da escassez de mão de obra qualificada, entre a necessidade de atração de estrangeiros e a rígida política de fiscalização das fronteiras para conter a entrada de migrantes clandestinos. O caráter seletivo dessa política, que discrimina e marginaliza os estrangeiros que não são bem-vindos, é um dos temas centrais do filme analisado.

\section{O submundo dos trabalhadores migrantes no Reino Unido}

Coisas belas e sujas aborda os deslocamentos globais e o envolvimento involuntário de dois migrantes em situação irregular em Londres com o tráfico internacional de órgãos humanos. O filme expõe a vulnerabilidade de migrantes e refugiados, cujas vidas encontram-se presas numa fronteira difusa e perigosa entre o cerco dos fiscais da imigração e o assédio do crime organizado. Entre os inúmeros caminhos possíveis para analisar um filme como este, o nosso trabalho de interpretação levou em conta dois aspectos: de um lado, o contexto de produção do filme e, de outro, a construção dos personagens, os símbolos e as metáforas que articulam a narrativa fílmica e os cenários nos quais a ação se desenvolve. Para articularmos os diálogos do filme com o mundo social e os sentidos que o filme constrói internamente, utilizamos como suporte as metodologias de leitura fílmica desenvolvidas pelo sociólogo e historiador do cinema Pierre Sorlin e pelo historiador Marc Ferro. O cinema, para Sorlin, é um modo de escritura fílmica da história que incorpora elementos ficcionais e históricos bem como a visão de mundo do diretor e dos atores. ${ }^{7}$ Assim,

\footnotetext{
7 Pierre Sorlin (1977) vai até mais além ao sugerir que é difícil a separação entre filme histórico e filme de ficção. Para Sorlin (ibidem), todo filme é ao mesmo tempo histórico e de ficção, pois mesmo que o cineasta se baseie em documentos, ele sempre preenche o filme com a sua imaginação.
} 
as imagens cinematográficas contribuem não só para a compreensão da história, mas também para a sua construção. Sorlin (1977) propõe uma abordagem semiótica do cinema, sugerindo que um filme é uma floresta de signos que devem ser articulados para a compreensão interna, estética e da linguagem do cinema. Esta metodologia nos permite desvendar a linguagem dos filmes e extrair informações que uma leitura desinformada não permitiria (ibidem). Já o historiador francês Marc Ferro (1992) propõe uma abordagem contextualista de um filme, para perceber os diálogos que este mantém com o mundo social. Para o entendimento do cinema é preciso ver num filme o que é e o que não é o filme. Para Ferro (ibidem), o filme é aquilo que pode ser visto na tela, é a trama, a iluminação, as interpretações, os figurinos, os planos, etc. E o que não é o filme é tudo aquilo que não podemos ver, ou seja, o contexto de produção, os esquemas de financiamento, os regimes políticos, a visão de mundo do diretor, enfim, todo um universo de significações que pulsa num filme, mas que não pode ser visto na tela (ibidem). ${ }^{8}$

Esta perspectiva de abordagem, ou o uso combinado das duas metodologias, nos possibilita compreender a construção interna do discurso fílmico e as relações do filme com os debates que ocorriam na sociedade inglesa e na Europa naquele momento sobre as migrações. Em 2002, quando o filme foi lançado, o tema da migração ocupava o centro dos debates no Reino Unido e na Europa. Desde 2001, o Partido Trabalhista - então no poder - colocou a migração no centro de seu enérgico programa legislativo. O mandato de Tony Blair (1997-2007) trouxe mudanças significativas para o modelo de imigração. A evolução das políticas foi no sentido de um forte compromisso com a gestão da migração para obter ganhos macroeconômicos e o desenvolvimento de uma estrutura de segurança robusta, que combatesse a migração não autorizada e reduzisse a busca de asilo. ' Já a nível europeu, diante do aumento expressivo dos fluxos migratórios para o continente, discutia-se os benefícios e os prejuízos que a chegada de estrangeiros acarretava para os diversos países.

\footnotetext{
${ }^{8}$ Para Ferro, observa Eduardo Morettin (2007: 40), “o cinema é um testemunho singular de seu tempo, pois está fora do controle de qualquer instância de produção, principalmente o Estado. Mesmo a censura não consegue dominá-lo. O filme, para o autor, possui uma tensão que lhe é própria, trazendo à tona elementos que viabilizam uma análise da sociedade diversa da proposta pelos seus segmentos, tanto o poder constituído quanto a oposição".

${ }^{9}$ Só no ano de 2002 três marcos legislativos importantes foram estabelecidos: 1) a definição de uma reforma abrangente sobre as migrações, incluindo o objetivo de uma "migração gerenciada"; 2) o aumento das restrições ao asilo e novos poderes de aplicação da legislação, mas o registo de apoio à migração econômica; 3 ) a criação de um programa de imigração que visava atrair migrantes altamente qualificados (Somerville, 2007).
} 
Em meio às polêmicas, o filme de Frears chamou a atenção para dois aspectos correlatos da migração: a necessidade de mão de obra para os trabalhos menos valorizados e, ao mesmo tempo, a brutal exploração e marginalização a que estão submetidos os migrantes irregulares que ocupam temporariamente estes empregos.

Stephen Frears já havia lançado um olhar sobre o tema, em 1985, com Minha adorável lavanderia (My Beautiful Laundrette, no original), explorando diferentes dimensões da amizade e do romance, entre um garoto punk inglês e um migrante paquistanês de segunda geração. Ambientado na era Thatcher, nos subúrbios do sul de Londres numa época marcada, ao mesmo tempo, pelo desemprego - provocado pelo desmonte das indústrias pesadas - e pelo estímulo à cultura empresarial, o filme aborda a luta da comunidade paquistanesa, já estabelecida na capital inglesa, para preservar a sua identidade numa sociedade que oferecia a possibilidade da ascensão para aqueles que estavam dispostos a abandonar suas tradições (Graham, 2015).

Com Coisas belas e sujas, quase 20 anos depois, Frears abordou o lado mais pesado das migrações e das relações entre os migrantes em situação irregular, habitantes do submundo de Londres. Okwe (interpretado por Chiwetel Ejiofor) é um médico nigeriano que deixou Lagos devido a problemas políticos e vive na capital britânica trabalhando de dia como taxista, com licença falsa, e de noite como recepcionista de um hotel. O táxi que Okwe dirige não é o emblemático carro preto, oficial de Londres, mas um carro comum de passageiros, dirigido em diferentes turnos por estrangeiros com carteiras falsificadas. Nos poucos momentos de descanso entre as duas jornadas de trabalho, Okwe exerce clandestinamente e a contragosto a medicina para socorrer pessoas que, como ele, vivem à margem do sistema de saúde britânico. Os pacientes, em geral, são homens, estrangeiros ilegais, portadores de doenças venéreas. As consultas são coletivas, rápidas, num ambiente inadequado e agenciadas pela pessoa que administra o serviço de táxis. Se no seu país Okwe era médico e gozava de um certo prestígio, em Londres é um "cidadão" de segunda classe. Divide ilegalmente um pequeno apartamento com Senay (interpretada por Audrey Tatou), uma migrante turca, islâmica e casta, que vive driblando os inspetores da imigração, trabalha ilegalmente como faxineira no mesmo hotel e é explorada sexualmente pelos patrões, que também são migrantes.

Okwe e Senay representam uma categoria particular de migrantes. Não são turistas ou viajantes ocasionais, não são trabalhadores qualificados, desejados nas "cidades globais" e não possuem vistos de permanência. 
Integram os que, contrariando a utopia de um mundo de mobilidade sem fronteiras (Castles, 2010), ${ }^{10}$ não têm o direito de circular livremente pelo mundo e deixaram seus países para fugir de algum problema social ou político. Okwe é um refugiado político, que deixou involuntariamente a Nigéria por causa de problemas com o governo, enquanto Senay se encaixa melhor no conceito de migrante voluntária, que tenta mudar de vida em outro país, seguindo o exemplo da prima que vive em Nova Iorque e trabalha num café italiano. Ambos podem ser definidos como migrantes globais: estão em constante movimento e não cultivam - por diferentes motivos - laços identitários mais sólidos com o país que os acolhe. A situação deles é diferente da dos personagens de Minha adorável lavanderia, migrantes paquistaneses que, sem abrir mão de suas identidades, lutam por reconhecimento, cidadania e um lugar ao sol na capital britânica. Os paquistaneses da era Thatcher, mesmo lidando com a discriminação, não estavam de passagem. Seus vínculos na e com a sociedade que os acolheu eram mais sólidos e cultivavam fortes laços étnicos de comunidade.

Embora Coisas belas e sujas dialogue com a migração de uma maneira mais ampla, o contexto mais imediato é o do mandato de Tony Blair como primeiro-ministro, período no qual o Partido Trabalhista colocou o tema da imigração no centro do seu ambicioso e severo programa legislativo, sobretudo a partir de 2001 (Somerville, 2007). O governo Blair apostou numa gestão econômica da migração, procurando atrair trabalhadores com qualificações escassas no Reino Unido e, ao mesmo tempo, na securitização da migração, investindo em tecnologia, como a biometria, e estabelecendo um controle mais rígido nas fronteiras para desestimular a migração clandestina. O governo Blair esforçou-se também por reduzir o número de pessoas que pediam asilo, intensificando o controle do regime de vistos nos países de trânsito e nos de origem, aumentando a multa para os transportadores e reduzindo os benefícios sociais. Depois dos ataques do 11 de Setembro, o combate à migração ilegal endureceu com o lançamento de novas medidas, dificultando a entrada sem o visto e cobrando regulamentação dos estrangeiros residentes no Reino Unido. Em 2006, a pressão aumentou ainda mais com a aprovação de

${ }_{10}$ Por isso, Stephen Castles, diferentemente de alguns analistas das formas de mobilidade global contemporâneas que defendem o abandono do termo migração para descrever a circulação de pessoas no mundo no século XXI, considerada uma época de maior fluidez e abertura, ainda acha "apropriado abordar as migrações como processos baseados na desigualdade e discriminação, e controlados e limitados pelos Estados” (2010: 15). 
sanções severas contra os empregadores que contratavam estrangeiros em situação irregular (Somerville, 2007). ${ }^{11}$

É neste ambiente de recrudescimento da política imigratória que os personagens de Frears se movem. Os apuros e os constrangimentos sofridos por Okwe e Senay para escapar da antipática e rigorosa fiscalização, o modo como os agentes de imigração são retratados (vingativos, insensíveis e facilmente enganáveis) e as sutilezas narrativas que criam imediata identificação dos espectadores com os protagonistas, deixam claro que o filme é uma crítica condenatória das posturas do Estado britânico em relação às migrações. A situação de Senay é particularmente emblemática para pensar os paradoxos da lei de imigração do Reino Unido e a vigilância constante sobre os trabalhadores ilegais e seus empregadores. A vulnerabilidade da migrante é decorrente da situação indefinida: pula de subemprego em subemprego para escapar ao cerco das autoridades e é chantageada pelos patrões que, para obterem favores sexuais, ameaçam denunciá-la aos serviços de imigração. Perseguida pelos fiscais da imigração, ela abandona o emprego de camareira a arranja outro de costureira numa pequena manufatura de roupas, que também é fiscalizada com frequência. Apesar do cerco da legislação e da intensa vigilância, não faltavam ofertas de trabalho, não declarado, para pessoas como ela que, diante da recusa ou do não interesse dos trabalhadores ingleses, ocupavam temporariamente estas vagas.

A narrativa de Coisas belas e sujas é organizada em torno das experiências e dos olhares de Okwe e Senay. Eles não são apenas vítimas silenciosas que desempenham papeis secundários na trama. Frears deu voz àqueles que quase sempre estão calados e sobre os quais os protagonistas falam. Eles tomam a palavra e falam, com pesado sotaque, da sua condição de estrangeiros, exprimem seus valores, desencantos e desferem, em tom ácido, críticas à cidade que os acolhe e os rejeita, que os abriga e os abandona, que precisa da sua força de trabalho, mas os exclui dos direitos, que precisa dos seus corpos e lhes sequestra os órgãos. A Londres que vemos emergir no filme é a cidade que as suas experiências e subjetividades percorrem, percebem e descrevem.

\footnotetext{
${ }^{11}$ Um episódio ocorrido no mandato de David Cameron (2010-2016) ilustra com certa ironia o descompasso entre a rigidez das leis anti-imigração e a presença vital dos estrangeiros ilegais no Reino Unido. Mark Harper, ministro da imigração, encarregado de aplicar uma política mais severa de imigração pelo governo, sustentou que o trabalho ilegal enfraquece as empresas legítimas e favorece a exploração. Em fevereiro de 2014, Harper renunciou ao cargo depois de vir a público que sua faxineira era uma imigrante ilegal. Harper era conhecido pela forma agressiva com que implementava a política anti-imigração do governo, o que tornou a situação ainda mais embaraçosa (The Guardian, 2014).
} 


\section{Um coração humano entupindo as artérias da política britânica de imigração}

Num trabalho de rotina no hotel, para resolver um problema de entupimento, Okwe encontra um coração humano largado na latrina do banheiro. A descoberta, que deflagra uma trama policial envolvendo tráfico de órgãos, prostituição e migração ilegal, é também a imagem icônica no filme: o coração na latrina denuncia o caráter descartável da vida humana. Mais do que isso, a imagem exprime visceralmente a condição do migrante: ele vale tanto quanto um dejeto humano.

O coração jogado fora é o artifício dramático que revela uma rede suja, criminosa, articulada internacionalmente, que comercializa órgãos humanos e explora a vulnerabilidade e a ilegalidade dos estrangeiros. O hotel é a base de operações da rede criminosa. As cirurgias clandestinas e a entrega dos órgãos extraídos acontecem nas dependências do estabelecimento e contam com a cumplicidade ou o silêncio dos funcionários, irregulares na maioria. O hotel se metamorfoseia num hospital clandestino, para cirurgias ilegais e criminosas, destinado a extrair partes dos corpos daqueles que entram no jogo e decidem trocar um órgão por um passaporte falso. O gerente do hotel, um sujeito inescrupuloso chamado Juan, é um migrante legal, bem estabelecido, que comanda a rede, explorando a situação irregular da outra parcela de migrantes. Frears desnuda a exploração feroz, frequentemente esquecida, dos migrantes recém-chegados por aqueles que já se encontram em condições estáveis e gozando de certos privilégios. É o caso também do dono da pequena manufatura de roupas, um migrante em situação regular, que emprega mulheres estrangeiras clandestinamente, sem as declarar e que as chantageia para obter favores sexuais.

O tráfico de órgãos se articula numa rede global que conecta pessoas de várias partes do mundo. Numa ponta da rede estão os clientes, compradores de órgãos, dispostos a pagar 10 mil libras por um rim. O caráter internacional da organização se torna explícito quando ficamos sabendo que um dos compradores é da Arábia Saudita. Na outra ponta, estão os migrantes dispostos a trocar um rim por documentos falsos que lhes permitam permanecer no Reino Unido e desfrutar dos benefícios da "legalidade". Entre os clientes endinheirados e os migrantes desesperados, articula-se uma zona intermediária especializada no recrutamento dos "doadores", na receptação e na falsificação de documentos - os falsificadores de passaportes, por exemplo, são libaneses.

O comércio internacional de órgãos humanos, tornados mercadorias, no filme e no mundo globalizado, flui nas geografias dramaticamente desiguais de poder mundial. Para Nancy Scheper-Hugues (2000), a prática 
ocorre num espaço transnacional, envolve doadores de órgãos, receptores, corretores, intermediários, com conexões criminosas em alguns casos, e segue os novos caminhos do capital e das tecnologias na economia global. Em geral, o fluxo de órgãos é orientado do Sul para o Norte, do terceiro para o primeiro mundo, do pobre para o rico, do preto e castanho para o branco, e da mulher para o homem (ibidem). O filme sugere um fluxo de órgãos, decorrente das estruturas globais de vulnerabilidade, que flui também em outras direções. O tráfico recruta migrantes - oriundos do Sul do mundo - em cidades globais como Londres, que por sua vez negociam os órgãos, que se destinam, por exemplo, à Arábia Saudita. No caso já mencionado que ocorre no filme, é a situação de desespero dos estrangeiros ilegais no dito "Primeiro Mundo" e o poder do dinheiro no "Sul" que alimenta o tráfico. O comércio ilegal de órgãos foi favorecido pelo desenvolvimento da cirurgia de transplantes que, como bem observou Shapiro (2009), é uma conquista ambígua na medida em que tanto pode salvar como comprometer vidas. Se de um lado a cirurgia estende a vida daqueles que podem pagar pelos caros procedimentos médicos, de outro, a vida daqueles de quem os órgãos são extraídos está sob severa coação. Embora abominável, os fluxos globais de órgãos são facilitados pela expansão da economia mundial, que afeta a fronteira mutável da interface cultura-economia (ibidem).

Esse lado sujo e perverso da imigração ilegal tem, no filme, o seu oposto. Entre os migrantes que não se envolvem com a prática criminosa e lutam para manter a dignidade sem precisar de mutilar o corpo, constitui-se uma rede de amizades e solidariedade que os ajuda a enfrentar a dura condição que a ilegalidade impõe. As redes migratórias, vistas como um conjunto de laços pessoais e sociais que conectam pessoas, são fundamentais na articulação dos processos migratórios. Os laços, que podem ser de natureza étnica, familiar, de amizade ou de experiência de trabalho, engendram formas de solidariedade que constituem e mantêm as redes ativas. ${ }^{12}$ Senay decidiu partir para Londres, sugere o filme, tomando o exemplo da prima que migrou para Nova Iorque. E de Londres, depois de escapar, com a ajuda de Okwe, do cerco armado por Juan, partiu para Nova Iorque, ao encontro da prima.

\footnotetext{
${ }^{12}$ Massey (1988: 396; tradução do autor) definiu as redes migratórias como "um conjunto de laços interpessoais que ligam migrantes, antigos migrantes e não migrantes nas áreas de origem e de destino, por meio de vínculos de parentesco, amizade e conterraneidade”. Para Kelly (1995: 219; tradução do autor), redes migratórias são "agrupamentos de indivíduos que mantêm contatos recorrentes entre si, por meio de laços ocupacionais, familiares, culturais ou afetivos. Além disso, são formações complexas que canalizam, filtram e interpretam informações, articulando significados, alocando recursos e controlando comportamentos".
} 
A rede que conecta Okwe e Senay, e os seus poucos "amigos", se constituiu na sociedade receptora, Londres, e é formada por laços de amizade (o amigo chinês), de trabalho e residenciais (ambos dividiam um pequeno apartamento). Este tipo de rede de apoio entre pessoas que não se conheciam é fundamental, como podemos ver no filme, para a sobrevivência diante das adversidades impostas pela ilegalidade. A rede criminosa articula-se num espectro completamente diferente. Ao invés da solidariedade e da ajuda, ela se constitui como rede de exploração da condição do migrante (exploração sexual, do trabalho e da vulnerabilidade social).

\section{Um necrotério de calor humano na fria Londres da migração ilegal}

No universo sombrio, frio, sujo e criminoso de precarização da vida representado no filme, o único ambiente onde Okwe encontra algum conforto e um pouco de calor humano é, paradoxalmente, no necrotério de um hospital. O necrotério é um signo que - interpretado no interior da trama e articulado com os modos de significação da condição dos migrantes - é revelador do discurso fílmico sobre a relação dos personagens com a sociedade que os cerca. No imaginário popular, o necrotério é um lugar frio, triste, lúgubre, associado à perda de pessoas queridas. Na cultura cinematográfica, invariavelmente, os necrotérios são de dar arrepios. São lugares assustadores, explorados nos filmes de terror para provocar o medo e arrancar calafrios das plateias. Isso sem falar nas incontáveis narrativas de fantasmas e assombrações que circulam mundo afora envolvendo necrotérios. O necrotério pode ainda ser definido, na antropologia da supermodernidade de Marc Augé, ${ }^{13}$ como um dos muitos não lugares da nossa contemporaneidade, ou seja, um lugar de passagem que não possibilita a construção de laços identitários.

No filme de Frears, o paradoxo é apenas aparente. São para esquecer os clichês cinematográficos. A perspicaz inversão semiótica produz um efeito oposto ao senso comum alimentado pelos filmes de terror e suspense. Naquele lugar supostamente frio e sem vida trabalha Guo Yi, um migrante chinês, tranquilo e educado, amigo de Okwe. É ali que o médico nigeriano vai, nas poucas horas vagas, para ter com quem conversar, conseguir remédios para os seus pacientes do submundo, jogar xadrez e, numa hora de aperto, ter uma cama quente para dormir. De lugar da morte, o necrotério se converte num refúgio seguro, onde o protagonista encontra abrigo, calor humano e compaixão. O necrotério de Frears contrasta com o mundo dos

${ }_{13}$ Marc Augé (2012) prefere o uso da expressão "supermodernidade" ao termo pós-modernidade porque considera que este último confere uma noção incorreta de ruptura e é mais descritivo do que analítico. 
vivos, com a indiferença e a frieza das relações humanas e com a invisibilidade social do migrante.

No necrotério, os mortos, independentemente da cor, da condição social e da nacionalidade, são tratados com deferência e dignidade. Guo Yi prepara os corpos respeitosamente, observando a religião e os ritos fúnebres de cada um. Na sequência em que prepara o corpo de um homem chinês, sem família, ele diz para Okwe, enquanto costura o terno: "Cortei os botões para o espírito dele poder sair e costuro os bolsos para não levar o seu azar para o mundo dos mortos. Se ele for ateu, estraguei um terno que ninguém vai ver. Se for budista, estou lhe dando a felicidade eterna pelo preço de um pedaço de linha". Uma bela lição de respeito em relação à diferença e de cuidado com o próximo, mesmo que morto, numa sociedade que, no discurso fílmico, trata os imigrantes como seres descartáveis.

Se os necrotérios podem ser descritos como "não lugares", onde os corpos sem vida, e, portanto, sem identidade, são depositados à indiferença da morte, Guo Yi e Okwe aprenderam a arte de transformar um desses lugares num espaço tecido de amizade, respeito e solidariedade. $\mathrm{O}$ uso invertido dos símbolos associados ao necretório tem o efeito de sublinhar a frieza e a indiferença que paira no mundo dos vivos.

\section{4. "Como é que eu nunca te vi?": a invisibilidade social e a invisibilidade tática}

Coisas belas e sujas é um filme sobre a vida precária, improvisada e instável dos migrantes irregulares em Londres. A narrativa fílmica foi construída em torno das experiências dos dois personagens centrais e dos seus círculos de relacionamentos, nos locais de trabalho ou nas moradias provisórias. Os únicos ingleses com os quais mantêm alguma forma de contato são os fiscais da imigração. Patrões e colegas de trabalho, amigos eventuais ou pessoas com quem dividem moradias, são todos migrantes regulares ou irregulares. A vida destes migrantes corre à margem da sociedade inglesa, num mundo paralelo, clandestino. Um mundo invisível, de pessoas imperceptíveis, embora a sua força de trabalho seja fundamental para movimentar a economia e qualificar a mão de obra da cidade global. ${ }^{14}$ No ano de 2002 , quando o filme foi lançado, uma polêmica em torno da imigração opunha setores do governo e

\footnotetext{
${ }^{14}$ Um estudo da University College London, divulgado em 2014, mostrou que a chegada de trabalhadores estrangeiros no Reino Unido injeta dinheiro na economia britânica e aumenta o número de profissionais qualificados no país (BBC/Brasil, 2014). Indo assim de encontro aos argumentos contra a entrada de migrantes, que impactariam negativamente a economia e provocariam a precarização da mão de obra, os responsáveis pelo estudo "estimam que a imigração tenha gerado um superávit de quase 23 bilhões de libras (cerca de $\mathrm{R} \$ 92$ bilhões) na economia britânica entre os anos de 2000 e 2011, sustentado pelo pagamento de impostos" (ibidem).
} 
economistas. Discutia-se a proposição de uma política única na União Europeia para dificultar o acesso de imigrantes na Europa. Enquanto parte do governo se esforçava para impedir a entrada de mais migrantes, economistas ingleses afirmavam a necessidade de atraí-los para compor a força de trabalho. Segundo os economistas, a vinda dos migrantes gerava um crescimento econômico sustentado, aliviava déficits de determinadas profissões e mantinha a inflação sob controle. Peter Robinson, economista-chefe do Instituto de Pesquisas em Políticas Públicas afirmou que "A chegada deles cria empregos que de outras maneiras não estariam ali” (apud Thomas, 2002).

Além disso, os migrantes tendem a desempenhar funções para as quais os ingleses, num contexto de baixo desemprego, não se mostram interessados. Em 2002, as taxas de desemprego eram significativamente baixas e apenas $3,1 \%$ da força de trabalho recorria ao seguro-desemprego, a menor taxa desde 1975. Numa situação como esta, os empregadores encontram dificuldades para contratar trabalhadores. Atraí-los com melhores salários dispara a inflação. A vinda de estrangeiros, de acordo com os economistas, traz expectativas de crescimento econômico e manutenção da inflação sob controle (Thomas, 2002).

Se para os economistas a entrada de migrantes, num ambiente de desemprego em baixa, ajuda no controle da inflação e alimenta a economia, no âmbito social, além de gozarem de poucos direitos, são discriminados e/ou tratados com indiferença. Num diálogo relâmpago com um inglês - um dos raros que aparece no filme - Okwe exprime breve e eloquentemente a condição de invisibilidade. O inglês pergunta: "Como é que eu nunca vi vocês antes?". Okwe responde: "Porque somos gente que vocês não veem. Nós dirigimos seus táxis, limpamos seus quartos e chupamos seus paus". Okwe sente na pele e denuncia, ao desinteressado interlocutor, a invisibilidade social a que pessoas como ele estão submetidas. Os migrantes estão por toda parte, nas ruas, nos hotéis, nos ônibus, nos restaurantes, limpando a sujeira, servindo às mesas, mas são tratados com desprezo ou indiferença, como se não existissem. A invisibilidade social pode ser definida, metaforicamente, como a condição de quem não é visto, de quem passa despercebido socialmente. Estão ali, presentes de corpo, ocupando certos espaços, mas são imperceptíveis nas relações sociais.

A invisibilidade dos migrantes é determinada pelas profissões que ocupam, pela classe, pela etnia, pelo idioma e pelo status legal (Hovet, 2006). $\mathrm{Na}$ hierarquia das relações sociais, atravessadas por relações de poder, eles ocupam os lugares menos prestigiados. Embora desempenhem funções vitais para as economias locais e prestem serviços sem os quais as cidades enfrentariam dificuldades, não são reconhecidos socialmente. $\mathrm{O}$ adjetivo vital 
não é apenas força de expressão. Aponta para uma relação de vida e morte dos migrantes com as sociedades receptoras, que passa pela exploração do corpo como força de trabalho e, em alguns casos, até como reserva de órgãos.

As funções que desempenham estão ligadas à dimensão biológica da vida da cidade (recolher o lixo, limpar as latrinas, cozinhar), à força física (construção civil, portos), ao lazer e à vida sexual (prostituição). A ênfase na dimensão biológica faz com que o coração na latrina e o tráfego de órgãos retirados dos migrantes em Coisas belas e sujas ganhem mais sentido ainda. Eles, os migrantes, literalmente dão vida, a sua vida, à Europa. Mesmo assim, não são vistos. São fantasmas que vagueiam de emprego em emprego, de um canto para outro, com múltiplas identidades. Quando Okwe retorna à praça de táxi, depois de uma jornada de trabalho, e entrega a carteira de motorista e o carro para outro colega africano que carrega uma cruz no pescoço, ele brinca: "Seu nome agora é Mohammed". Ambos riem e o colega sai para cumprir a sua jornada. A brincadeira é na verdade uma advertência sobre a troca de identidades: a que fica ali, e que provavelmente nem é a original, e a que está prestes a assumir quando entra no carro. Dirigindo o carro, todos são negros, todos são Mohammeds.

Há, no entanto, uma categoria para a qual os migrantes não são invisíveis: os oficiais da imigração, os únicos ingleses que os enxergam e realmente prestam atenção às suas vidas. Talvez por isso Okwe tenha chamado a atenção do colega, ainda que em tom de brincadeira. No filme, Okwe e Senay são chamados, ou procurados, pelos nomes e identificados por fotografias. Seus passos e suas histórias de vida são conhecidos. Mantê-los à vista é mantê-los sob o controle do Estado. A visibilidade é uma estratégia de poder e uma política de controle, que implica na estigmatização, nos constrangimentos, na vigilância panóptica, na sensação permanente de observação e perseguição e nas frequentes ameaças de deportação. Por conta disso, os personagens esforçam-se por passar despercebidos.

Visibilidade e invisibilidade são um jogo de espelhos entre os migrantes e a sociedade em que vivem. Se, por um lado, não são vistos socialmente e, por conta disso, lhes é negada a identidade, por outro, quando na condição de ilegais, procuram se manter invisíveis aos olhos da fiscalização. Senay vive nas sombras, esgueirando-se agilmente pelas paredes, com os ombros curvados, de cabeça baixa, para não ser notada. A expressão corporal é a de quem procura a invisibilidade. A discrição de Okwe é defensiva. Manter-se invisível significa proteger sua verdadeira identidade e manter-se fora do alcance da panoptia estatal. Neste caso, a invisibilidade é um recurso tático de sobrevivência para escapar às estratégias da política de imigração que coloca os migrantes dentro de um campo de visibilidade 
e de previsibilidade. ${ }^{15}$ Quando Okwe se faz passar por faxineiro (dupla invisibilidade), num movimentado hospital, para ter acesso a remédios sem ser notado, ninguém desconfia. Numa outra situação, quando Guo Yi lhe entrega uma carteira de identidade falsa e ele estranha a foto, o amigo lhe diz: "preto é preto". E tudo fica subentendido entre eles. A fala de Juliette, a prostituta que, embora não sendo migrante, se identifica com a condição dos estrangeiros ilegais e deles se aproxima, vai na mesma direção. Ela pede que Okwe mande alguém verificar um vazamento no quarto que acabou de usar num programa. Ele pergunta: "Algum problema?". Ela responde: "Como vou saber? Eu não existo, não é?". Nos três casos, o fato de não serem percebidos pode se transformar numa vantagem a ser explorada para se obter pequenas vitórias por meio de pequenos delitos. "Delitos de solidariedade" - com o perdão do trocadilho - que se justificam, no interior da trama, para correr em auxílio do próximo ou por conta da situação involuntária com que foram enredados na rede criminosa.

\section{Identidades em trânsito e não lugares do mundo global}

Coisas belas e sujas começa e termina num aeroporto. Nenhuma casualidade. Frears, pelo que se depreende do filme, e dos locais de filmagem, está a par dos debates contemporâneos sobre os espaços e a mobilidade no mundo globalizado. Cinematograficamente, e afinado com abordagens recentes, o aeroporto exprime a condição de transitoriedade e de não pertencimento dos personagens. Estar ali é estar num entre-lugares - entre Lagos e Londres, entre a Turquia e o Reino Unido. Logo, é estar em lugar nenhum, o que sugere o caráter instável e fluído das identidades, pois as construções identitárias estão ligadas aos lugares que nos são próprios.

$\mathrm{Na}$ sequência de abertura do filme, em meio aos sons, informes e chamadas, Okwe percorre furtivamente o saguão do aeroporto oferecendo serviço de táxi para os recém-chegados. Numa rápida conversa com dois homens, ele diz: "Não vim buscar vocês, mas eu resgato os esquecidos pelo sistema". Esta é uma das muitas frases provocativas lançadas por Okwe, que sugerem sua própria condição e a consciência que dela tem. A maneira desinibida como aborda as pessoas e a menção de lugares famosos de Londres a possíveis passageiros sugerem que o trabalho no aeroporto é rotineiro.

Nas cenas finais, Okwe e Senay, em fuga, portando passaportes falsificados, com falsas identidades, se despedem no aeroporto, declarando à distância o

${ }_{15}$ Uso livremente os conceitos de tática e estratégia, da forma como foram desenvolvidos por Michel de Certeau (1994). Michel Shapiro, numa entrevista a Lorenzo Rinelli, sugeriu que a invisibilidade dos personagens (que de alguma forma reflete sua falta de poder), ironicamente, se torna um ativo, porque eles podem mover-se em certos espaços sem chamar a atenção (Shapiro, 2009). 
amor um pelo outro. A condição irregular, e a marginalidade decorrente, não lhes permitem viver o amor, ou qualquer experiência afetiva mais duradoura. A migrante turca embarca para Nova Iorque, com identidade e passaporte italianos, para começar uma nova vida na cidade dos seus sonhos "com táxis amarelos, luzes nas árvores e policiais em cavalos brancos" - tal como Londres já tinha sido um dia. $\mathrm{O}$ aeroporto, por ser um lugar de passagem, de pessoas em trânsito, partindo ou chegando, é, por excelência, o não lugar. Se o lugar, na percepção do antropólogo Marc Augé (2012: 73), "pode se definir como identitário, relacional e histórico”, o não lugar é o oposto. Os lugares estão ligados às identidades, aos afetos, àquilo que nos constitui, histórica e socialmente, como seres humanos. Os não lugares - como os aeroportos, os necrotérios, as redes de hotéis, os supermercados, etc. - são espaços de passagem, de circulação. O hotel onde os personagens trabalham, visto desta maneira, encerra uma metáfora: como espaço de passagem parece sugerir as características de transitoriedade das migrações globais. A própria cidade de Londres cada vez mais é experimentada como um espaço de efemeridade e se torna, para os novos migrantes, uma cidade-hotel, para residentes temporários, e não propriamente um lar, como o fora para os migrantes da era pós-imperial (Graham, 2011). As identidades fugidias e provisórias de Okwe e Senay encontram, no aeroporto e no hotel, a expressão metafórica da sua tradução. As identidades não são apenas abandonadas - como no caso de Okwe, que vive com nome e documentos falsos - elas podem ser compradas, negociadas, trocadas, falsificadas. A identidade vira uma mercadoria nas mãos dos que a negoceiam (como para Juan, o gerente do hotel) e uma moeda de troca nas mãos dos estrangeiros ilegais.

Ainda no aeroporto, depois de despedir-se de Senay, Okwe liga para a filha Valerie, em Lagos, dizendo que está voltando para casa. A casa, o lar, a cidade de Lagos, como opostos aos não lugares, são o seu lugar no mundo. "A volta ao lugar", sugere Augé (2012: 98), "é o recurso de quem frequenta os não lugares". Depois de experimentar a solidão e o anonimato nos muitos não lugares da cidade global, Okwe está voltando para onde estão os seus afetos, para o que lhe é íntimo e familiar, onde ele tem um nome (embora não o possa usar) e uma profissão reconhecida (embora não a possa exercer). Mesmo assim, ele diz para a filha: "Valerie? Sim, sou eu. Finalmente... vou voltar para casa".

Depois de uma temporada infernal no submundo londrino, Okwe e Senay escapam da teia criminosa e encontram a redenção, ainda que provisória: ela embarca para uma nova oportunidade e ele retorna à Nigéria para reencontrar a filha. A redenção vem na forma da retomada do périplo migratório que os retira da condição de imobilidade em que se encontravam. Embora tenham encontrado uma saída para a situação à qual estavam presos, 
o final está longe de um happy end. Como migrantes globais, invisíveis e em constante movimento, suas vidas e identidades continuam em trânsito, de não lugar em não lugar, em busca do seu lugar no mundo.

Revisto por Ana Sofia Veloso

\section{Referências bibliográficas}

Agier, Michel (2006), "Refugiados diante da nova ordem mundial", Tempo Social, 18(2), 197-251. Tradução de Paulo Neves.

Augé, Marc (2012), Não lugares. Introdução a uma antropologia da supermodernidade. Campinas: Papiros. Tradução de Maria Lúcia Pereira [orig. 1992].

BBC/BRASIL (2014), "Imigração 'traz dinheiro e mão-de-obra qualificada para a economia'”, BBC News Brasil, 5 de novembro. Consultado a 14.01.2017, em http://www. bbc.com/portuguese/noticias/2014/11/141105_imigra_grana_fd.

Castles, Stephen (2010), "Entendendo a migração global. Uma perspectiva desde a transformação social”, Revista Internacional de Mobilidade Humana, XVIII(35), 11-43.

Certeau, Michel de (1994), A invenção do cotidiano: artes de fazer. Petrópolis: Vozes. Tradução de Ephraim Ferreira Alves [orig. 1990].

Ferro, Marc (1992), Cinema e história. Rio de Janeiro: Paz e Terra. Tradução de Flávia Nascimento [orig. 1977].

Foucault, Michel (1987), Arqueologia do saber. Rio de Janeiro: Forense-Universitária. Tradução de Luiz Filipe Baeta Neves [orig. 1969].

Graham, James (2011), "Postcolonial Purgatory: The Space of Migrancy in Dirty Pretty Things", in Andrew Teverson; Sara Upstone (orgs.), Postcolonial Spaces: The Politics of Place in Contemporary Culture. London: Palgrave Macmillan, 131-147.

Grimson, Alejandro (2011), "Doce equívocos sobre las migraciones", Nueva Sociedad, 233, 34-43. Consultado a 20.01.2017, em http://nuso.org/articulo/ doce-equivocos-sobre-las-migraciones/.

Hily, Marie-Antoinette (2003), "As migrações contemporâneas: dos estados e dos homens". Comunicação apresentada no "Seminário Cultura e Intolerância”, 18, 19 e 20 de novembro, SESC Vila Mariana, São Paulo, Brasil. Consultado a 06.12.2016, em https://hal.archives-ouvertes.fr/hal-00609853.

Hovet, Ted (2006), "The Invisible London of Dirty Pretty Things; or Dickens, Frears, and Film Today", Literary London: Interdisciplinary Studies in the Representation of London, 4(2). Consultado a 14.12.2016, em http://www.literarylondon.org/londonjournal/september2006/hovet.html.

Kelly, Patricia Fernández (1995), "Social and Cultural Capital in the Urban Ghetto: Implications for the Economic Sociology of Immigration", in Alejandro Portes (org.), The Economic Sociology of Immigration. New York: Russell Sage, 213-247. 
Le Goff, Jacques (1984), “Documento/monumento”, in Ruggiero Romano (dir.), Enciclopédia Einaudi. Volume 1: Memória - História. Lisboa: Imprensa Nacional-Casa da Moeda, 95-106.

Massey, Douglas (1988), "Economic Development and International Migration in Comparative Perspective”, Population and Development Review, 14(3), 383-413.

Morettin, Eduardo (2007), "O cinema como fonte histórica na obra de Marc Ferro", in Maria Helena Capelato; Eduardo Morettin; Marcos Napolitano; Elias Thomé Saliba (orgs.), História e cinema. São Paulo: Alameda, 39-64.

Napolitano, Marcos (2007), "A escrita fílmica da história e a monumentalização do passado: uma análise comparada de Amistad e Danton”, in Maria Helena Capelato; Eduardo Morettin; Marcos Napolitano; Elias Thomé Saliba (orgs.), História e cinema. São Paulo: Alameda, 65-83.

ONU News (2016), "Número de migrantes internacionais chega a cerca de 244 milhões", 12 de janeiro. Consultado a 22.03.2021, em https://news.un.org/pt/ story/2016/01/1537511-numero-de-migrantes-internacionais-chegou-244-milhoes.

Ordaz, Pablo (2016), "Quase 3.000 imigrantes morreram este ano no Mediterrâneo", El País, 22 de julho. Consultado a 17.12.2016, em http://brasil.elpais.com/brasil/2016/07/22/internacional/1469184421_996319.html.

Shapiro, Michael (2009), “'To Get What We Have Lost': A Discussion with Michael J Shapiro on Cinema and Politics", JGCCinema.com - Cinema and Globalization. Entrevista concedida a Lorenzo Rinelli. Consultada a 14.12.2016, em https://www.academia. edu/1799000/To_Get_What_We_Have_Lost_in_conversation_with_Michael_J_Shapiro.

Scheper-Hughes, Nancy (2000), "The Global Traffic in Human Organs”, Current Anthropology, 41(2), 191-224. Consultado a 14.01.2017, em http://www.jstor.org/ stable/10.1086/300123?seq=1\#page_scan_tab_contents.

Somerville, Will (2007), "The Immigration Legacy of Tony Blair", Migration Policy Institute, 10 de maio. Consultado a 08.01.2016, em http://www.migrationpolicy.org/ article/immigration-legacy-tony-blair.

Sorlin, Pierre (1977), Sociologie du cinéma. Paris: Éditions Aubicr Montaigne.

The Guardian (2014), "Immigration Minister Resigns for Employing Ilegal Immigrant”, 8 de fevereiro. Consultado a 14.01.2016, em https://www.theguardian.com/ uk-news/2014/feb/08/immigration-minister-resigns-illegal-immigrant-mark-harper.

Thomas, Emma-Ross (2002), "Imigração ajuda economia britânica, dizem analistas", Reuters, 14 de junho. Consultado a 04.12.2016, em https://noticias.uol.com.br/inter/ reuters/2002/06/14/ult27u23118.jhtm.

\section{Filmes}

Frears, Stephen (1985), My Beautiful Laundrette. Working Title Films, SAF Productions, Channel Four Films.

Frears, Stephen (2002), Dirty Pretty Things. BBC Films, Celador Film, Jonescompany Productions. 
Artigo recebido a 10.12.2019

Aprovado para publicação a 21.01.2021

\author{
Paulo Rogério Melo de Oliveira \\ Universidade do Vale do Itajaí \\ Rua Uruguai, 458 - Centro - Itajaí, Santa Catarina, Brasil \\ Contacto: paulo_rmo@hotmail.com \\ ORCID: https://orcid.org/0000-0003-0311-8349
}

\section{The Dark Side of Irregular Migration to the United Kingdom in the Film Dirty Pretty Things}

The article proposes an interpretation of the 2002 film, Dirty Pretty Things, by British filmmaker Stephen Frears, understanding it as a political stand on global migratory movements and, in particular, the English migration policy of the early 21 st century. The film depicts undocumented migrants barely surviving in London through precarious, temporary jobs and back-breaking workdays who involuntarily engage in the international trafficking of human organs and forged passports. The methodology of film analysis combines Marc Ferro's contextualist approach, which invites us to explore the dialogues of the film with the social world, with the semiotic proposal of Pierre Sorlin, with the help of which we interpret the signs and metaphors that build the internal meanings of the film narrative. Keywords: cinema; cinematographic representation; illegal migrants; migrations; United Kingdom.

\section{Le côté sombre de la migration irrégulière au Royaume-Uni dans le film Loin de chez eux}

Dans cet article, on propose une interprétation du film de 2002 Loin de chez eux (Dirty Pretty Things dans le titre original), du cinéaste britannique Stephen Frears, en le comprenant comme une prise de position politique sur les mouvements migratoires mondiaux et, en particulier, par rapport à la politique migratoire britannique du début du XXI e siècle. Dans le film, des migrants sans papiers, qui survivent à Londres grâce à des emplois précaires et temporaires et des journées de travail exténuantes, sont involontairement impliqués dans le trafic international d'organes humains et de passeports falsifiés. La méthodologie d'analyse filmique combine l'approche contextualiste de Marc Ferro, qui nous invite à explorer les dialogues du film avec le monde social, avec la proposition sémiotique de Pierre Sorlin, à l'aide de laquelle nous interprétons les signes et les métaphores qui construisent les significations internes du récit filmique. Mots-clés: cinéma; migrants clandestins; migrations; représentation cinématographique; Royaume-Uni. 
